
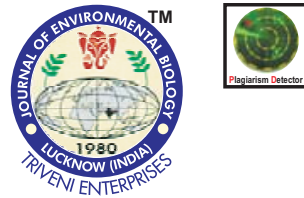

DOI : http://doi.org/10.22438/jeb/39/1/MRN-491

\title{
Evaluation of certain non- conventional plant based oils against red spider mite of tea
}

ISSN: 0254-8704 (Print) ISSN: 2394-0379 (Online) CODEN: JEBIDP

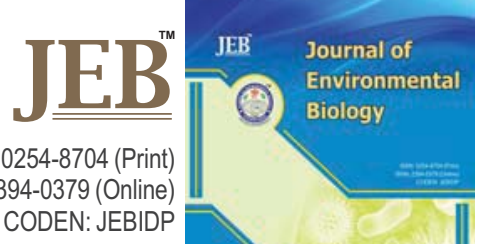

Authors Info

S. Roy, G. Handique*, F.R. Bora and A. Rahman

Department of Entomology, Tocklai Tea Research Institute, Jorhat- 785 008, India

${ }^{*}$ Corresponding Author Email : handique.gautam@yahoo.com

Key words

Acaricides

Oligonychus coffeae

Ovicide

Plant based oils

Tea

Publication Info

Paper received : 19.10.2016

Revised received : 23.02.2017

Accepted : 01.07.2017

\section{Abstract}

Aim : Red spider mite, Oligonychus coffeae is considered as one of the most severe and persistent pest of tea. To limit the use of synthetic acaricides against the pest and to promote alternative pest control strategies using natural products, the present study aimed to determine the anti-mite properties of seven plant based oils viz., castor oil, sesame oil, rose oil, olive oil, mustard oil, groundnut oil and karanja oil against 0 . coffeae.

Methodology : Red spider mites were collected from a commercial tea garden of Jorhat, Assam, India. Bioassays were performed on adults and eggs of 0 . coffeae with 5 to 7 different concentrations of plant oils. Mortality data was expressed by Abbott's formula and lethal concentration of $50 \%$ mortality $\left(\mathrm{LC}_{50}\right)$ was calculated using Finney probit analysis and expressed in ppm.

Results : Among the plant oils, karanja oil was the most toxic adulticide followed by mustard oil and olive oil. The egg hatchability was significantly affected in all treatments with rose oil being most toxic ovicide among the plant oils followed by karanja oil and olive oil. Further, their bioefficacy was comparable to synthetic insecticide, ethion.

Interpretation: The data suggest that the selected plant oils have potential to control tea red spider mite, and therefore could be effectively utilized in integrated pest management programme envisaged for tea mite.

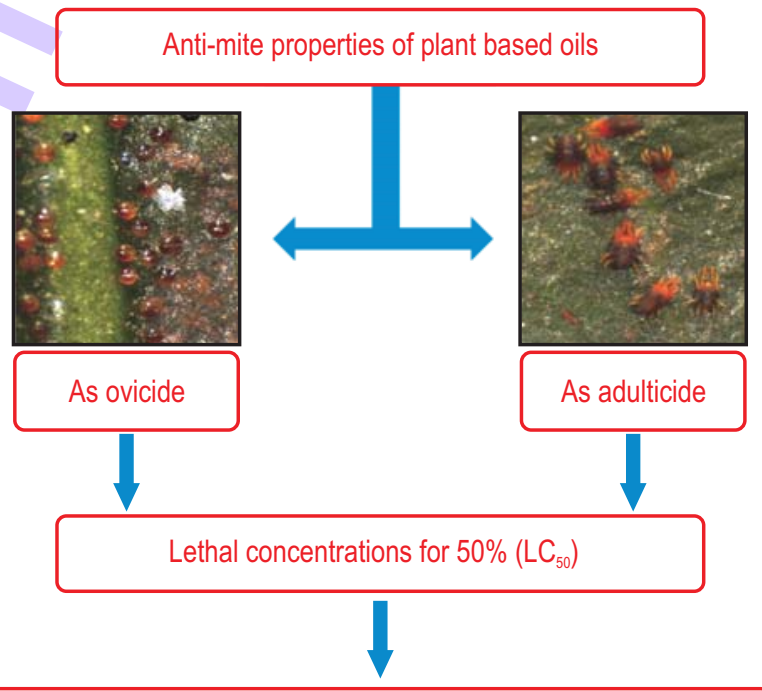

Plant based oils have potential for controlling red spider mite 


\section{Introduction}

Red spider mite, Oligonychus coffeae Nietner (Tetranychidae : Acarina), a worldwide polyphagous acari, is reported to be a severe pest of tea of many tea growing countries. Adults and nymphs of $O$. coffeae lacerate cells on the upper surface of mature tea leaves along the mid rib and veins leading to high defoliation and debilitation of tea bush, resulting in crop loss of $17 \%$ to $46 \%$ (Roy et al., 2014). To manage 0 . coffeae, application of synthetic acaricides has been widely adopted. Extensive use of chemicals against this pest has led to a number of problems like resistance development, environmental contamination, health hazards, increased cost of application etc. (Hazarika et al., 2009). Additionally, tea being an important export commodity has to be in compliance with the international regulations on pesticide usages (Roy et al., 2010).

These problems have necessitated the development of new chemicals with novel modes of action and effective biodegradable properties. There is a rising trend for use of natural pesticides which are derived from plants or micro-organisms, since they are considered safe than synthetic chemicals (Radhakrishnan and Prabhakaran, 2014). Among the natural pesticides, plant-derived oils are reported as potential alternative compounds for pest control. Several plant oils contain lipophilic compounds that have direct contact and fumigant actions (Rajendran and Sriranjini, 2008) and acetyl-cholinesterase (AChE) inhibitory activities (Owokotomo et al., 2015) against specific pests (Isman, 2000; Kostyukovsky et al., 2002; Mukesh et al., 2014). They are also considered to be relatively safe because they have minimal impact on human and animal health and act at multiple and novel target sites, resulting in reduced resistance development (Han et al., 2006).

Efficacies of plant based oils have been used to suppress mite pest populations, as well as some insects (Koul et al., 2008). However, the effect of plant based oils on 0 . coffeae has not been studied till date. In view of the above, a laboratory study was carried out to examine the effects of seven plant based oils viz., castor oil, sesame oil, rose oil, olive oil, mustard oil, groundnut oil and karanja oil against 0 . coffeae in terms of their acaricidal and ovicidal activities.

\section{Materials and Methods}

Maintenance of $\boldsymbol{O}$. coffeae: The mites were collected from the tea gardens of Tocklai Tea Research Institute, Jorhat, Assam, India. A culture of red spider mite was maintained in the laboratory following the detached leaf culture method of Helle and Sabelis (1985). From the stock, spider mites were transferred onto fresh tea leaf $\left(6 \mathrm{~cm}^{2}\right)$ placed on moistened cotton pads in plastic trays $(42 \times 30 \times 6.5 \mathrm{~cm})$. Rearing trays were kept under controlled conditions where temperature was maintained at $25 \pm 2^{\circ} \mathrm{C}, 75 \pm 5 \% \mathrm{RH}$, and $16 \mathrm{~L}$ : $8 \mathrm{D}$ photoperiod. Water was added to the rearing trays as and when necessary to keep the cotton moist. Withered leaves were replaced with new ones at regular interval.

Adulticidal bioefficacy : The assay was carried out by leaf disc method (Ebeling and Pence, 1953). Mature tea leaves of TV1 clone were collected from Tocklai experimental garden and brought to laboratory. The leaves were then washed with distilled water and air dried. Three leaf discs $(2 \mathrm{~cm}$ diameter) each representing replicates of different treatments were placed over a wet cotton pad placed in a Petri plate $(9 \mathrm{~cm}$ diameter) with its ventral surface down. Thirty adult mites were released on each disc with a camel hair brush and allowed to settle. A final count of mite population was taken after $4 \mathrm{hrs}$. Mites were initially exposed to a wide range of concentrations, and on the basis of the resulting mortality, a series of concentrations with narrower ranges were tested further. The second series was determined on the basis of the concentrations causing mite mortality above $20 \%$ and below $100 \%$. The different concentrations of aqueous solutions of plant oils (purchased from local market) and control (distilled-water) were sprayed on the leaf using a glass atomizer (constant pressure $2.5 \mathrm{~kg} \mathrm{~cm}^{-2}$ ). To all concentrations, 3 to 4 drops of teepol (Teepol- AG®, National Organic Chemical Industries Ltd., Mumbai, India) was added as an emulsifier. Synthetic acaricide, ethion 50 EC (Tafethion®, Rallis India Ltd., Mumbai, India) was used as a standard. The entire procedure was replicated three times. Final assessment was made after $48 \mathrm{hrs}$ of application and expressed as per cent mortality of mites at each dose in relation to control mortality using Abbott's formula (Abbott, 1925). Lethal concentrations for $50 \%\left(\mathrm{LC}_{50}\right)$ were calculated using statistical package for social (SPSS) version 10.0 (SPSS Inc., USA), based on Finney ProbitAnalysis (Finney, 1973) and expressed in ppm.

Ovicidal bioefficacy : For the assessment of ovicidal properties, leaf discs ( $20 \mathrm{~mm}$ diameter) were placed over water soaked cotton pad. Fifteen gravid female mites were introduced on the leaf discs and kept overnight for oviposition. After $24 \mathrm{hrs}$, the introduced mites were removed with the help of fine camel hair brush. The eggs laid on leaf discs were counted under microscope for bioassay. Thirty eggs per leaf was selected for treatment and subjected to spraying with different concentrations of plant oils using a glass atomizer (constant pressure $2.5 \mathrm{~kg} \mathrm{~cm}^{-2}$ ) and control (water). After drying for $30 \mathrm{~min}$, the discs were placed at $27^{\circ} \pm 2^{\circ} \mathrm{C}$ and $65 \pm 5 \% \mathrm{RH}$ and examined daily for 12 successive days. Hatchability was recorded for both experimental and control batches of eggs. Those eggs which did not hatch after this period were regarded as non-viable. Each treatment was replicated three times and ethion was used as a standard to compare the results. Lethal concentrations for $50 \%\left(\mathrm{LC}_{50}\right)$ were calculated using the statistical package for social (SPSS) version 10.0 (SPSS Inc., USA), based on Finney ProbitAnalysis (Finney, 1973) and expressed in ppm.

\section{Results and Discussion}

Botanical insecticide contain compounds that exhibit ovicidal, repellent, antifeedent and toxic effects in insects (Isman, 
Table 1 : Relative toxicity of different oils against adult mite (Oligonychus coffeae) population

\begin{tabular}{|c|c|c|c|c|c|}
\hline Treatment & $\mathrm{n}^{\mathrm{a}}$ & Slope \pm SE & $\mathrm{LC}_{50}(\mathrm{ppm})$ & $95 \% \mathrm{FL}^{\mathrm{b}}$ of $\mathrm{LC}_{50}$ (Upper-Lower) & $\mathrm{x}^{2}$ \\
\hline Karanja oil & 90 & $0.71 \pm 0.005$ & 117.241 & $250.211-54.930$ & 0.543 \\
\hline Mustard oil & 90 & $0.58 \pm 0.004$ & 345.706 & $757.746-157.721$ & 1.133 \\
\hline Olive oil & 90 & $0.45 \pm 0.003$ & 360.045 & $949.328-136.551$ & 0.157 \\
\hline Sesame oil & 90 & $0.90 \pm 0.007$ & 386.186 & $689.472-216.310$ & 0.943 \\
\hline Castor oil & 90 & $0.79 \pm 0.005$ & 1131.41 & $2006.420-637.999$ & 0.844 \\
\hline Groundnut oil & 90 & $0.80 \pm 0.003$ & 1493.47 & $2600.963-857.550$ & 0.747 \\
\hline Rose oil & 90 & $1.30 \pm 0.004$ & 2042.65 & $2936.530-1420.860$ & 1.340 \\
\hline Ethion & 90 & $1.76 \pm 0.013$ & 441.891 & $502.642-371.561$ & 4.270 \\
\hline
\end{tabular}

$\mathrm{LC}_{50}=$ lethal concentration for $50 \% ;{ }^{b} \mathrm{FL}=$ Fiducial limit

Table 2 : Ovicidal toxicity of different oils against eggs of adult mite (Oligonychus coffeae) population

\begin{tabular}{|c|c|c|c|c|c|}
\hline Treatment & $\mathrm{n}^{\mathrm{a}}$ & Slope \pm SE & $\mathrm{LC}_{50}(\mathrm{ppm})$ & $95 \% \mathrm{FL}^{\mathrm{b}}$ of $\mathrm{LC}_{50}$ (Upper-Lower) & $x^{2}$ \\
\hline Rose oil & 90 & $0.89 \pm 0.004$ & 5622.5 & $9125.77-3464.03$ & 0.5694 \\
\hline Karanja oil & 90 & $0.98 \pm 0.005$ & 6927.6 & $10760.00-4460.21$ & 0.9999 \\
\hline Olive oil & 90 & $0.57 \pm 0.007$ & 7403.5 & $15559.12-3522.78$ & 4.83 \\
\hline Castor oil & 90 & $1.18 \pm 0.003$ & 10124 & $14727.93-6950.31$ & 0.3301 \\
\hline Groundnut oil & 90 & $0.97 \pm 0.004$ & 11881 & $18732.41-7536.06$ & 2.5441 \\
\hline Mustard oil & 90 & $1.05 \pm 0.005$ & 12133 & 18490.33-7961.44 & 2.1814 \\
\hline Sesame oil & 90 & $0.68 \pm 0.006$ & 18216 & $34538.73-9607.18$ & 0.2243 \\
\hline Ethion & 90 & $1.33 \pm 0.005$ & 2270 & $5916.92-2080.13$ & 0.114 \\
\hline
\end{tabular}

$\mathrm{LC}_{50}$, lethal concentration for $50 \%$; ${ }^{\mathrm{n}} \mathrm{n}=$ Number of individuals; ${ }^{\mathrm{b}} \mathrm{FL}=$ Fiducial limit

2006) and have long been recommended as alternative to chemical pesticides for pest management. Insecticidal constituents of many plant oils are monoterpenoids that defend plants against plant directed pathogens, herbivores or competing plant species (Ahn et al., 1998). Adulticide bioassay of different oil concentrations on red spider mites (Table 1) showed lowest $\mathrm{LC}_{50}$ value (117.24 ppm) in case of karanja oil followed by mustard oil (345.70 ppm), olive oil (360.04 ppm), sesame oil (386.18 ppm), ethion (441.891 ppm), castor oil (1131.41 ppm) and groundnut oil (1493.47 ppm), while the highest $\mathrm{LC}_{50}$ value was observed in case of rose oil (2042.65 ppm). Roy et al. (2016) reported potential anti-mite properties of jatropha oil and garlic oil against the same pest with $\mathrm{LC}_{50}$ values of 118.54 ppm and 312.40 ppm, respectively. In this study, karanja oil, mustard oil, olive oil and sesame oil also exhibited similar type of toxicities in the mite population. The toxic effect of these oils may be due to their fumigant (Rajendran and Sriranjini, 2008; Ayvaz et al., 2010) and/or contact toxicities (Kim et al., 2003) of the major components of these oils or by inhibition of AChE activitites. Some authors also report that monoterpenoids present in oils cause insect mortality by inhibiting acetylcholinesterase enzyme activity (Sertkaya et al., 2010) possibly by activation of octopaminergic receptors (Kostyukovsky et al., 2002). As this target site is not shared with mammals, most essential oil chemicals are relatively non-toxic to mammals and fish and meet the criteria for "reduced risk" pesticides (Koul et al., 2008).
The results of the present study on ovicidal action on eggs of $O$. coffeae indicated significant reduction in adult emergence and the bioassay results showed that rose oil had the lowest $\mathrm{LC}_{50}$ value (5622.5 ppm) which was followed by karanja oil (6927.6 ppm) < olive oil $(7403.5 p p m)<$ castor oil $(10124$ ppm $)<$ groundnut oil (11881 ppm) < mustard oil (12133 ppm) < sesame oil (18216 ppm). LC L $_{50}$ values registered for egg stage of red spider mite against ethion was 2270 ppm (Table 2). Plant based oils, in general, possess excellent ovicidal properties and found to be effective even at few parts per million (Benelli, 2015) as demonstrated against eggs of Mediterranean flour moth and red spider mite wherein oils of Ziziphora clinopodioides, Jatropha curcas and Allium sativum showed outstanding oviposition deterrence and ovicidal activity even at low concentrations (Kheirkhah et al., 2015; Roy et al., 2016), confirming the current findings.

The present investigation indicated that, among all the plant oils tested, karanja oil showed the lowest $\mathrm{LC}_{50}$ value against the adult mites of $O$. coffeae, thereby representing high toxicity of the components. The oil possess an active flavone compound 'karanjin' which has anti-insect activities (Perumalsamy et al., 2015). It also showed ovicidal action against the eggs of 0 . coffeae, which is in agreement with the report of Pavela (2009) where $100 \%$ mortality was observed on using $1 \%$ and $3 \%$ of karanja oil against Tetranychus urticae. It was observed that oil, methanolic seed extract, acetone leaf extract, aqueous seed 
extract, chloroform seed extract and petroleum ether seed extract of Pongamia pinnata acted as oviposition deterrents, antifeedants and larvicides against a wide range of insect pests (Pavela, 2007). Also, sesame and rose oil showed high acaricidal, ovicidal and oviposition deterrence activities against red spider mite in the present study.

The results of the present investigation suggest that plant based oils have potential for controlling 0 . coffeae. Further, determination of chemical compositions of plant oils and field studies are needed for the development of new class of compounds in developing an eco-friendly and environmentally safe method for the management of red spider mite.

\section{Acknowledgment}

This research was partially supported by the Seed Division, Department of Science and Technology, Government of India in the form of a project [SP/YO/014/2015(C)].

\section{References}

Abbott, W.S.: A method of computing the effectiveness of an insecticide. J. Econ. Entomol., 18, 265-267 (1925).

Ahn, Y.J., S.B. Lee, H.S. Lee and G.H. Kim: Insecticidal and acaricidal activity of caravacrol and $\beta$-thujaplicine derived from Thujopsis dolabrata var. hondai sawdust. J. Chem. Ecol., 24, 81-90 (1998).

Ayvaz, A., O. Sagdic, S. Karaborklu and I. Ozturk: Insecticidal activity of the essential oils from different plants against three stored-product insects. J. Insect Sci., 10, 21 (2010).

Benelli, G.: Plant-borne ovicides in the fight against mosquito vectors of medical and veterinary importance: a systematic review. Parasitol. Res., 114, 3201-3212 (2015).

Ebeling, W. and R.J. Pence: Pesticide formulation: influence of formulation on effectiveness. J. Agric. Food Chem., 1, 386-397 (1953).

Finney, D.J.: Probit Analysis. $2^{\text {nd }}$ Edn., Cambridge University Press, United Kingdom (1973).

Han, M.K., S.I. Kim and Y.J. Ahn: Insecticidal and antifeedant activities of medicinal plant extracts against Attagenus unicolor japonicus (Coleoptera: Dermestidae). J. Stored Prod. Res., 42, 15-22 (2006).

Hazarika, L.K., M. Bhuyan and B.N. Hazarika:. Insect pests of tea and their management. Annu. Rev. Entomol., 54, 267-284 (2009).

Helle, W. and M.W. Sabelis: Spider mites: Their biology, natural enemies and control. $1^{\text {st }}$ Edn., Elsevier Science Publishing Company, New York, USA(1985).

Isman, M.B.: Plant essential oils for pest and disease management. Crop Prot., 19, 603-608 (2000).

Kheirkhah, M., V. Ghasemi, A.K. Yazdi and S. Rahban: Chemical composition and insecticidal activity of essential oil from Ziziphora clinopodioides Lam. used against the Mediterranean flour moth, Ephestia kuehniella Zeller. J. Plant Prot. Res., 55,
260-265 (2015).

Kim, S., C. Park, M.H. Ohh, H.C. Cho and Y.J. Ahn: Contact and fumigant activities of aromatic plant extracts and essential oils against Lasioderma serricorne (Coleoptera: Anobiidae). J. Stored Prod. Res., 39, 11-19 (2003).

Kostyukovsky, M., A. Rafaeli, C. Gileadi, N. Demchenko and E. Shaaya: Activation of octopaminergic receptors by essential oil constituents isolated from aromatic plants: possible mode of action against insect pests. Pest Manag. Sci., 58, 1101-1106 (2002).

Koul, O., S. Walia and G.S. Dhaliwal: Essential oils as green pesticides: Potential and constraints. Biopest. Int., 4, 63-84 (2008).

Mukesh, Y., P. Savitri, R. Kaushik and N.P. Singh: Studies on repellent activity of seed oils alone and in combination on mosquito, Aedes aegypti. J. Environ. Biol., 35, 917-922 (2014).

Owokotomo, I.A., O. Ekundayo, T.G. Abayomi and A.V. Chukwuka: Invitro anti-cholinesterase activity of essential oil from four tropical medicinal plants. Toxicol. Rep., 2, 850-857 (2015).

Pavela, R.: Effectiveness of some botanical insecticides against Spodoptera littoralis Boisduvala (Lepidoptera: Noctuidae), Myzus persicae Sulzer (Hemiptera: Aphidae) and Tetranychus urticae Koch (Acari: Tetranychidae). Plant Prot. Sci., 45,161-167 (2009).

Pavela, R.: Possibilities of botanical insecticide exploitation in plant protection. Pest Technol., 1, 47-52 (2007).

Perumalsamy, H., M.J. Jang, J.R. Kim, M. Kadarkarai and Y.J. Ahn: Larvicidal activity and possible mode of action of four flavonoids and two fatty acids identified in Millettia pinnata seed toward three mosquito species. Parasites Vect., 8, 237 (2015).

Phasomkusolsil, S. and M. Soonwera: Insect repellent activity of medicinal plant oils against Aedes aegypti (Linn.), Anopheles minimus (Theobald) and Culex quinquefasciatus say based on protection time and biting rate. SoutheastAsian J. Trop. Med. Pub. Hlth., 41, 831-840 (2010).

Radhakrishnan, B. and P. Prabhakaran: Biocidal activity of certain indigenous plant extracts against red spider mite, Oligonychus coffeae (Nietner) infesting tea. J. Biopesticides, 7, 29-34 (2014).

Rajendran, S.V.S.: Plant products as fumigants for stored-product insect control. J. Stored Prod. Res., 44, 126-135(2008).

Roy, S., A. Mukhopadhyay and G. Gurusubramanian: Baseline susceptibility of Oligonychus coffeae (Acarina: Tetranychidae) to acaricides in North Bengal tea plantations, India. Int. J. Acarol., 36, 357-362 (2010).

Roy, S., G. Handique, A. Barua, F.R. Bora, A. Rahman and N. Muraleedharan: Comparative performances of jatropha oil and garlic oil with synthetic acaricides against red spider mite infesting tea. Proc. Natl. Acad. Sci., India, Sect. B Biol. Sci., doi:10.1007/s40011-016-0734-y (2016).

Roy, S., N. Muraleedharan and A. Mukhopadhyay: The red spider mite, Oligonychus coffeae (Acari: Tetranychidae): Its status, biology, ecology and management in tea plantations. Exp. Appl. Acarol., 63, 431-463 (2014)

Sertkaya, E., K. Kaya and S. Soylu: Acaricidal activities of the essential oils from several medicinal plants against the carmine spider mite (Tetranychus cinnabarinus Boisd.) (Acarina: Tetranychidae). Ind. Crops Prod., 31, 107-112 (2010). 